\title{
A Study of Effect of Glycaemic Status on Pulmonary Function Test in Type 2 Diabetes Mellitus
}

\author{
Basavaraj G.T. ${ }^{1}$, Mudassir Indikar², Malingaraya Negali $^{3}$ \\ 1,2,3 Department of General Medicine, Basaveshwara Teaching and General \\ Hospital, M. R. Medical College, Kalaburagi, Karnataka, India.
}

\section{ABSTRACT}

\section{BACKGROUND}

Diabetes mellitus is a metabolic disorder precipitating micro vascular, macro vascular complications and peripheral vascular diseases. Pulmonary complications of diabetes mellitus have been poorly characterised. Glycaemic status has shown varied impact on lung functions. In type- 2 diabetes there is resistance to insulin action and also inadequate insulin secretion. Diabetes mellitus is associated with morphological and functional abnormalities. Several studies have shown that diabetes is associated with impaired pulmonary function. Pulmonary complications of diabetes mellitus (DM) have been poorly characterised. Some authors have reported normal pulmonary functions and even concluded that spirometry is not at all necessary in diabetic patients. We wanted to highlight the evidence-based significance of spirometry

\section{METHODS}

This cross-sectional study was done for a period of 1 year from September 2017 to July 2018. The study sample consisted of 50 type- 2 diabetes patients and 50 controls.

\section{RESULTS}

A total of 100 subjects were included in the present study; 50 of them were diabetics and the other 50 were non-diabetic controls matched by age, sex and body mass index (BMI). The range of forced vital capacity (FVC) in diabetic group was from 1.36 litres, which is lesser than range in controls (2.06 litres). Forced expiratory volume (FEV1) / FVC ranged from 0.59 in diabetics compared to 0.84 in controls. Mean FVC value was higher in diabetics with a duration of diabetes of less than 5 years (2.72) as compared to those with diabetes of more than 5 years (2.03) with a P value of 0.0004 which is statistically significant.

\section{CONCLUSIONS}

Type 2 diabetes mellitus is associated with restrictive pattern of respiratory abnormality. As the duration of diabetes increases the restrictive profile was more prominent. There was inverse relation between glycaemic status and spirometric indices FEV1 and FVC. Thus, an intensive glycaemic management may reduce the risk of death through an improved ventilator function which is independent of the other beneficial effects.

\section{KEY WORDS}

Pulmonary Function Test, Type 2 Diabetes Mellitus, Glycaemic Status
Corresponding Author: Dr. Basavaraj G.T, Department of General Medicine, Basaveshwara Teaching and General Hospital, M. R. Medical College, Kalaburagi, Karnataka, India.,

E-mail: basavgt8@gmail.com

DOI: $10.14260 /$ jemds/2021/283

How to Cite This Article:

Basavaraj GT, Indikar M, Negali M. A study of effect of glycaemic status on pulmonary function test in type 2 diabetes mellitus. J Evolution Med Dent Sci 2021;10(18):13431346, DOI: $10.14260 /$ jemds/2021/283

Submission 22-10-2020,

Peer Review 05-03-2021,

Acceptance 12-03-2021,

Published 03-05-2021.

Copyright (C) 2021 Basavaraj G.T. et al. This is an open access article distributed under Creative Commons Attribution License [Attribution 4.0 International (CC BY 4.0)] 


\section{BACKGROUND}

The World Health Organization (WHO) estimates that more than 180 million people worldwide have diabetes, and by 2030 it is expected that this number will be doubled. ${ }^{1}$ There is an alarming increase in the incidence and prevalence of diabetes mellitus in Asian Indians. ${ }^{2}$ This metabolic disorder is a risk factor for precipitating micro vascular pathologies leading to autonomic neuropathy, nephropathy, retinopathy and peripheral neuropathy, and macro vascular pathologies leading to coronary artery disease, cerebrovascular accidents and peripheral vascular disease. ${ }^{3,4}$

Many studies suggested that lung is a target organ in DM and that glycaemic exposure is a strong determinant of reduced pulmonary function in DM patients theoretically, several pathological changes may affect the lungs in patients with DM. Many studies show that diabetes could lead to the development of pulmonary complications due to the collagen $\&$ elastin changes. Another theory suggested that micro angiopathy due to increase in enzymatic glycation of proteins and peptides of the extracellular matrix at chronic high circulating glucose levels may also have important role in the pathological changes of lungs in DM patients. The above pathophysiological mechanisms suggest that lung is also involved in diabetic subjects as target organ. ${ }^{5}$

Spirometry is a widely used pulmonary function test (PFT), ideally suited to describe the effects of obstruction or restriction of lung function. It is a powerful diagnostic tool that plays a significant role in the early diagnosis of lung damage and its associated structures. In spite of this, spirometry is not used routinely as part of a management system in diabetic patients. Its role is neither fully explored, nor fully utilised to achieve quality of life in managing diabetes mellitus. We wanted to highlight the evidence-based significance of spirometry. It may serve as a brief reference for diabetes management teams to enable spirometry to be included in the algorithm of the routine assessment of diabetic patients. These complications have a significant impact on the quality of life of the affected individuals and they impose a heavy burden on health care providers' worldwide. ${ }^{6}$

\section{METHODS}

This cross-sectional study was conducted over a period of one year from September 2017 to July 2018.

\section{Study Population}

50 type-2 diabetic patients who were not on insulin visiting Basaveshwar Teaching and General Hospital as in-patients \& out-patients were included. The sample size was taken based on the convenience of the study. 50 healthy controls who's fasting blood sugar (FBS) and postprandial blood sugar (PPBS) were in normal limits from administrative office of Basaveshwar Teaching and General Hospital, and other volunteers constituted the control group. The informed consent of the patient / guardian was obtained.

\section{Inclusion Criteria}

All patients presenting to medical outpatient department (OPD) and patients from inpatient department (IPD) at Basaveshwara Teaching and General Hospital who were proved cases of type 2 diabetes mellitus and not on insulin.

\section{Exclusion Criteria}

- Smokers.

- Previous history of lung disease.

- Signs and symptoms of respiratory infections at the time of test.

- $\quad$ History of being admitted during past six months with respiratory symptoms.

- History of significant cardiovascular illness.

- History of occupational exposure to any substances that could affect lung function.

Subjects were selected as per the inclusion and exclusion criteria. Their written consent was recorded. Their detailed history was taken. Age, height, weight, and BMI were recorded, and detailed general physical examination was done. Each patient was instructed to visit hospital with $8 \mathrm{hrs}$. of fasting, and the blood samples were drawn for estimation of FBS and glycated hemoglobina.

\section{Statistical Analysis}

Microsoft Excel and SPSS version 11 and Syst at 8.0 were used for the analysis of the data.

\section{RESULTS}

FBS among cases and controls were compared which shows a mean FBS value of $207.8 \mathrm{mg} / \mathrm{dl}$ in diabetic group as compared to a mean value of $97.42 \mathrm{mg} / \mathrm{di}$ in controls with $\mathrm{P}$ value of 0.000 which is highly significant.

\begin{tabular}{|llllll|}
\hline Variables & Groups & N & Mean & SD & P-Value \\
FBS (mg / dl) & Cases & 50 & 207.8 & 49.2718 & $0.0000^{*}$ \\
& Controls & 50 & 97.4222 & 5.1505 & \\
\multirow{2}{*}{ PPBS (mg / dl) } & Cases & 50 & 254.3333 & 48.7922 & $0.0000^{*}$ \\
& Controls & 50 & 126.7778 & 6.1529 & \\
\hline \multicolumn{4}{l}{ Table 1. Comparison of Cases and Controls with FBS and PPBS } \\
\hline
\end{tabular}

Post prandial blood sugars showed highly significant difference among both groups with mean of 254.3 among diabetic group and 126.77 among controls.

\begin{tabular}{|c|c|c|c|c|c|}
\hline Variables & $\begin{array}{c}\text { Group } \\
\text { s }\end{array}$ & $\mathbf{N}$ & Mean & SD & $\begin{array}{c}\text { P- } \\
\text { Value }\end{array}$ \\
\hline \multirow{2}{*}{ FVC (in litres) } & Cases & 50 & 2.4833 & 0.4396 & $0.0001^{*}$ \\
\hline & Controls & 50 & 2.9809 & 0.4324 & \\
\hline \multirow{2}{*}{ EV1 (in litres) } & Cases & 50 & 2.0791 & 0.4079 & $0.0001^{*}$ \\
\hline & Controls & 50 & 2.4347 & 0.3967 & \\
\hline \multirow{2}{*}{$\mathrm{FEV}_{1 /} \mathrm{FVC}$} & Cases & 50 & 0.8376 & 0.1014 & 0.2551 \\
\hline & Controls & 50 & 0.8171 & 0.0637 & \\
\hline \multicolumn{6}{|c|}{$\begin{array}{l}\text { Table 2. Comparison of Cases and Controls } \\
\text { with Regard to FVC, FEV and FEV } 1 \text { /FVC }\end{array}$} \\
\hline
\end{tabular}

The FVC in diabetic group, mean was 0.4396 lit, which was lesser than the range in controls. 
FEV1 was reduced in cases with mean of 2.0791 compared to controls with mean of 2.4347 with a P-value of 0.0001 being statistically significant.

\begin{tabular}{|cccccc|}
\hline Variables & Duration & N & Mean & SD & P-Value \\
& $\leq 5$ yrs. & 18 & 2.7237 & 0.3532 & $0.0004^{*}$ \\
& $>5$ yrs. & 32 & 2.3077 & 0.4176 & \\
& $\leq 5$ yrs. & 18 & 2.2526 & 0.3964 & $0.008^{*}$ \\
& $>5$ yrs. & 32 & 1.9523 & 0.3741 & \\
\multirow{2}{*}{$\mathrm{FEV}_{1 /} \mathrm{FVC}$} & $\leq 5$ yrs. & 18 & 0.8184 & 0.0884 & 0.2567 \\
& $>5$ yrs. & 32 & 0.8515 & 0.1166 & \\
\hline \multicolumn{5}{c}{ Table 3. Comparison of Duration (5 yrs. and > 5 yrs.) } \\
$\mathrm{FP}^{\mathrm{P}}<0.05$ & with FVC, FEy1 and FEV1 / FVC \\
\hline
\end{tabular}

Mean FVC value was higher in diabetics with duration of diabetes less than 5 years (2.72) as compared to those with diabetes for more than 5 years (2.03) with a P value of 0.0004 suggestive of high statistical significance. $\mathrm{FEV}_{1}$ values on an average was low in subjects with diabetes for more than 5 years (1.95) than in those with diabetes for less than 5 years (2.25) with statistically significant difference of $P$ value of 0.008. $\mathrm{FEV}_{1} / \mathrm{FVC}$ was less in diabetics with duration of more than 5 years which was not statistically significant compared to those with diabetes for less than 5 years. With increase in FBS there was a decrease in mean FVC although statistically not significant. FEV1 decreased with increase in FBS, however, not significant statistically. FEV1 FVC mean values showed a rising trend with rising FBS values.

\begin{tabular}{|cccccc|}
\hline PFT & Summ & $\mathbf{9 0}-$ & $\mathbf{1 1 0}-$ & $\mathbf{2 0 0}-$ & \multirow{2}{*}{ P-Value } \\
& ary & $\mathbf{1 1 0}$ & $\mathbf{2 0 0}$ & $\mathbf{3 0 0}$ & \\
FVC (in litres) & Mean & 2.81 & 2.51 & 2.4 & 0.4149 \\
& SD & 0.2 & 0.45 & 0.43 & \\
FEV1 (in & Mean & 2.2 & 2.09 & 2.02 & 0.9568 \\
litres) & & & & 0.42 & \\
& SD & 0.18 & 0.42 & 0.87 & \multirow{2}{*}{0.1458} \\
\hline FEV1 / FVC & Mean & 0.75 & 0.82 & 0.09 & \\
\hline \multicolumn{5}{r}{ Table 4. Comparison of FBS Subgroups on Pulmonary Function Test } \\
\hline
\end{tabular}

\begin{tabular}{|cccc|}
\hline $\begin{array}{c}\text { PFT \% } \\
\text { Predict }\end{array}$ & Cases & Control & P-Value \\
\hline $\mathrm{FVC}$ & $68.37 \pm 20.44$ & $92.74 \pm 25.37$ & $0.001^{*}$ \\
$\mathrm{FEV}_{1}$ & $81.39 \pm 22.34$ & $85.08 \pm 24.12$ & $0.008^{*}$ \\
$\mathrm{FEV}_{1} / \mathrm{FVC}$ & $79.84 \pm 10.67$ & $85.47 \pm 10.13$ & 0.429 \\
\hline Table 5. Effects of Diabetes on \% Predicted FVC, FEy1, FEV1 FVC \\
\hline
\end{tabular}

The mean \% of predicted FVC among the cases was 68.37 and 92.74 among the control group with P-value of 0.001 , which is statically significant. And \% predicted FEV1 among the cases was 81.39 and 85.08 among the control group with significant P-value of 0.008 .

\section{DISCUSSION}

Present study was undertaken to assess ventilatory function of subjects with diabetes mellitus in comparison to subjects without diabetes. Larger population-based studies have been more consistent, demonstrating reduced pulmonary functions in patients with an elevated plasma glucose level and diagnosis of DM.

Out of the total 100 cases studied 50 were diabetic subjects and 50 were non-diabetics. The number of male subjects (30) was same in both diabetic and non-diabetic groups. The number of females in study was 20, equal in both the groups. Hence, there was no significant difference among diabetics and controls with reference to the gender of subjects.

The age wise distribution of subjects was matched in both case and controls. Age group of 50 - 59 years was the largest. Study by Ortiz Aguirre et al. ${ }^{7}$ has proved that as age increases the pulmonary function test values decrease. In the present study, age has been ruled out as a confounding factor by considering age matched subjects in both diabetic and nondiabetic groups.

Comparison of subjects with reference to body mass index showed no significant difference in diabetic and non-diabetic group of patients. Mean value of FVC was low in both case and control groups in subjects with low BMI compared to those with higher BMI values. The mean FEV1 and FEV1 / FVC showed no significant difference in diabetic and non-diabetics with reference to BMI.

In the study by Crapo et al. ${ }^{8} \mathrm{BMI}$ in diabetic patients with target organ damage was high compared to those subjects without target organ damage. These subjects with target organ damage and high BMI had reduced mean pulmonary function parameters. The present study shows no significant difference in BMI values among diabetic and non-diabetics nullifying BMI as one of the confounding factors.

\section{Comparison of FEV1 with Other Studies among Diabetics and Controls}

The present study is in agreement with the previous studies in comparing FEV1 among diabetic and non-diabetics. The mean values of FEV1 are low in diabetic group subjects compared to controls. ${ }^{9}$ The present study is in agreement with Walter. E. Robert et al. who studied the relationship between diabetes mellitus and pulmonary function and showed a decrease in FEV1 by $27 \mathrm{~m} 1$ in diabetic subjects. ${ }^{10}$

Davis M.E. Timothy studied the pulmonary function and its association with type- 2 diabetes mellitus and showed an average decrease of $9.5 \%$ in FEV1 of diabetics. ${ }^{11}$

In diabetes mellitus thickening of the alveolar epithelium, pulmonary capillary basal lamina leading to pulmonary micro angiopathy and reduced pulmonary elastic recoil caused by non-enzymatic glycosylation of the connective tissue reduced the FEV1.12,13,14

Effect of Diabetes Mellitus on FEV1 / FVC Ratio The present study is in agreement with previous studies which have shown marginally high values of FEV1 / FVC in diabetic subjects when compared to age, sex and BMI matched controls.

The present study is in agreement with Walter. E. Robert et al. who studied the relationship between diabetes mellitus and pulmonary function, ${ }^{13}$ and showed a $1.5 \%$ increase in the FEV1 / FVC with a P value $<0.05 \%$ which is statically significant thus, suggesting a restrictive pattern of ventilatory impairment.

\section{CONCLUSIONS}

Even though patients of type 2 diabetes did not have any respiratory symptoms, they did have underlying subclinical 
restrictive pattern of lung functions. Type 2 diabetes mellitus is associated with restrictive pattern of respiratory abnormality. As the duration of diabetes increases, the restrictive profile was more prominent. There was inverse relation between glycaemic status and spirometric indices FEV1 and FVC. Thus, an intensive glycaemic management may reduce the risk of death through an improved ventilator function which is independent of the other beneficial effects. Spirometer remains a cost effective, a simple noninvasive diagnostic tool, and its judicious use can give warning signal to patients to take early preventive measures.

Hence, it is advisable for diabetic patients to undergo periodic spirometry tests to assess the severity of lung function impairment. These measures will help in preventing lung damage in initial stage and thus, contribute to reduction in morbidity and mortality in patients of type 2 diabetes.

Data sharing statement provided by the authors is available with the full text of this article at jemds.com.

Financial or other competing interests: None.

Disclosure forms provided by the authors are available with the full text of this article at jemds.com.

\section{REFERENCES}

[1] World Health Organization. Fact sheet: diabetes no. 312 2008.

http://www.who.int/mediacentre/factsheets/fs312/en/ index.html.

[2] King H, Aubert RE, Herman WH. Global burden of diabetes 1995 to 2025. Prevalence, numerical estimates and projections. Diabetes Care 1998;21(9):1414-31.

[3] Benbassat CA, Stern E, Kramer M, et al. Pulmonary function in patients with diabetes mellitus. Am J Med Sci 2001;322(3):127-32.
[4] Longo D, Fauci A, Kasper D, et al. Harrison's Principles of Internal Medicine. $18^{\text {th }}$ edn. Vol. 2. McGraw Hill Education 2011:2968-02.

[5] Sandler M. Is the lung a target organ in diabetes mellitus. Arch Intern Med 1990;150(7):1385-8.

[6] Mohan V, Sandeep S, Deepa R, et al. Epidemiology of type 2 diabetes: Indian scenario. Indian J Med Res 2007;125:217-30.

[7] Ortiz-Aguirre AR, Vargas MH, Torres-Cruz A, et al. Age related spirometric changes in diabetic patients. Rev Invest Clin 2006;58(2):109-18.

[8] Crapo RO, Jensen RL, Hegewald M, et al. Arterial blood gas reference values for sea level and an altitude of 1,400 meters. Am J Respir Crit Care Med 1999;160(5 Pt 1):152531.

[9] Verma S, Goni M, Kudyar RP. Assessment of pulmonary function in patients with diabetes mellitus. JK Science 2009;11(2):71-4.

[10] Walter RE, Beiser A, Givelber RJ, et al. Association between glycaemic state and lung function. Am J Respir Crit Care Med 2003;167(6):911-6.

[11] Davis TM, Knuiman M, Kendell P, et al. Reduced pulmonary function and its associations in type 2 diabetes. Diabetes Res Clin Pract 2000;50(2):152-9.

[12] Arulmozhi MS. Diabetes in elderly: pulmonary complications in elderly diabetics. Micro Labs Ltd Bangalore 2005:119-25.

[13] Lange P, Groth S, Kastrup J, et al. Diabetes mellitus, plasma glucose and lung function in a cross sectional population study. Eur Respir J 1989:2(1):14-9.

[14] Asanuma YS, Fujiya S, Ide H, et al. Characteristics of pulmonary function in patients with diabetes mellitus. Diabetes Res Clin Pract 1985;1(2):95-101. 